\title{
An Analysis of Critical Period Hypothesis in English Teaching
}

\author{
DENG Fei \\ Sichuan University of Arts and Science, Dazhou, China
}

\author{
ZHU Li-qin \\ Guizhou Normal University, Guiyang, China
}

\begin{abstract}
The Critical Period Hypothesis originated from biology and then was introduced into the field of linguistics. This paper introduces the concept of the Critical Period Hypothesis for language acquisition and some relevant literatures' research of Critical Period Hypothesis and English teaching in China as well as analyzing the research situation. From this contrast and analysis, the enlightenment from the Critical Period Hypothesis for language acquisition to English teaching in China is much easier to obtain. This paper determines that the influence of the Critical Period Hypothesis on second language acquisition and foreign language learning is still unclear.
\end{abstract}

Keywords: Critical Period Hypothesis, second language acquisition, English teaching

\section{Introduction}

The study of Critical Period Hypothesis for second language acquisition has great importance to English teaching in our country. Some scholars hold that the achievement of mastery and application of language needs constant learning. However, the best period of learning is approximately from 2 to 12 years old, which is a critical period for language acquisition. In that way, the Critical Period Hypothesis for second language acquisition comes into being. Over the next few decades, people will have completed a large number of researches in the Critical Period Hypothesis, and there are no lack of supporters and opponents toward the Critical Period Hypothesis for second language acquisition. It is certain that there are many scholars in our country who have studied this theory and applied it to English teaching. However, foreign language education of our country shows low aging tendency and toward whose pros and cons, experts in foreign language teaching field have controversy all the time.

\section{Literature Review}

The Critical Period Hypothesis for second language acquisition originated from studies in biology, which was first put forward by two neurobiologists, Penfield and Roberts (WANG, 2015). They believed that at some particular stage in people's lives they could acquire a language faster and easier in a natural environment where there is no exterior intervention and there are no people to teach (Fromkin, Rodman, \& Hyams, 1983). In the 1960s, this view was accepted and applied in the research area of second language acquisition by Lenneberg, which led to the influential theory: the Critical Period Hypothesis. He supposed that language was the product of the brain so the development of language ability was strictly restricted by the physiological basis of an individual (Lenneberg, 1967). Children who are older than two years old and younger than adolescence (10-12 years old)

DENG Fei, lecturer, MEd, School of Foreign Languages, Sichuan University of Arts and Science.

ZHU Li-qin, MEd, Institute of Foreign Languages Education, Guizhou Normal University. 
and whose brains are malleable are in the critical period for language acquisition. Johnson and Newport's findings (1989) have been accepted as the best evidence supporting the critical period in second language learning. In their study of critical period effects in learning a second language, Johnson and Newport admitted that a critical period for second language learning indeed exists. At that stage, learning language is an easy and natural process. When a child enters adolescence, his or her brain has fully matured and the nervous system is no longer flexible, which makes it be more and more difficult to learn a language. Therefore, there are more and more researchers at home and abroad further studying this problem using different subjects and all aspects of different point of views in various ways and experiment. These researches focus on whether or not there exists a critical period for second language acquisition. In other words, whether second language acquisition onset age is directly associated with the last results of language learning.

\section{The Debates on the Critical Period Hypothesis}

\section{The Opinions That Oppose the Critical Period Hypothesis for Second Language Acquisition}

Since the hypothesis was put forward, there have been many people who oppose it in the linguistics area. Ellis (2013) makes it clear that the view "the younger the children who start acquisition are, the easier language acquisition will be" (p. 22) is not totally correct. At best, it is partially correct. In fact, the advantage of language acquisition in a younger age simply exists in phonetics. However, some studies indicate that it has not yet formed a united conclusion in the problem when cerebral lateralization exactly happens and how much time on earth it needs to finish the process. On this account, the physiological neural basis of the Critical Period Hypothesis for language acquisition has been questioned. In 1975, a study done by Seliger, Krashen, and Ladefoged shows that adolescence may be a turning point of language learning. But Lenneberg's research results of the Critical Period Hypothesis for language acquisition neither proves that the critical period is based on brain development nor proves that second language learners in adulthood are certainly worse than children or cannot reach the level of native language in phonological acquisition. Snow and Hoefagel-hohle conduct the comprehensive research to the Critical Period Hypothesis for language acquisition in 1978. According to this hypothesis, first language acquisition has finished before brain lateralization and second language acquisition is relevantly faster and easier to succeed before adolescence. The subjects of the experiment are Dutch learners of different ages who speak British English. This research result is contrasted to the Critical Period Hypothesis for language acquisition. The problem is that the critical period for language acquisition remains to have no consistent study results. One of the most principal reasons is that there exists a difficulty in not being able to simply compare or contrast the results from different research methods. Despite the foreign studies, it is found that there are a large number of scholars who oppose the hypothesis, through analyzing the study of the Critical Period Hypothesis done by domestic scholars. For example, in the book Psycholinguistics, the author points, it is difficult to give an exact answer as for when is the best age to do foreign language learning (GUI, 2005). Therefore, we should study the learning characteristics of different stages and then apply the achievement comprehensively in teaching rather than simply drawing a conclusion in whether there exists the critical period. After a comprehensive analysis towards the studies at home and abroad, it is possible for people starting to learn a foreign language in any age to be successful (SHU, 2004). If an individual is learning a foreign language beginning at 12 years old, such learners could also reach or approach to the level of speaking native language on the condition of a good language 
environment and scientific teaching methods. Another scholar DAI Wei-dong also indicates that the language learning onset age nearly has no impact on the acquisition process. Beginners at all ages are capable to learn a foreign language well. In his opinion, the best stage for Chinese to learn a foreign language is between 12 and 15 years old. After a composite analyzing of the past decades researches of the Critical Period Hypothesis, WANG Li-fei supposes that the problems of whether there exists the critical period for second language acquisition and whether there exists different critical periods for different language skills need deeper and further study. In one of his essay, the critical period for second language acquisition does not exist (LIU, 2003). Although there are a large number of researches based on different methods, aims, and theoretical bases, it lacks enough proof to confirm that the hypothesis exists, even in phonological acquisition. Although the learners starting at an early age are better than those starting late, the results are from combined factors of many others rather the unilateral factor - the age. The research of CHEN Bao-guo (2001) also shows that even though there exists the critical period, the impact on second language acquisition should not be exaggerated.

\section{The Opinions That Support the Critical Period Hypothesis for Second Language Acquisition}

Some scholars that support the Critical Period Hypothesis for second language acquisition such as Oyama, Coppieters, and Patcowski (1978) have drawn relatively specific conclusions toward the age factor. They believe the hypothesis that the children who start to learn second language early will finally reach higher levels than the adults who start late has some supporting evidence but does not have any empirical disproof. Krashen (1982) also gives the same conclusion after summarizing plenty of experiment report related to foreign language learning. The research done by Johnson and Newport in 1989 is regarded as the best proof that supports the Critical Period Hypothesis in the area of second language acquisition. In their research, Johnson and Newport acknowledges that the critical period for second language acquisition really exists. They consider that people's ability begins to decay after six years old. The research result is from comparing 46 Chinese and Koreans who start to learn English, which is regarded as second language by them from different age groups. As a result, Johnson and Newport found that the age is a decisive factor that makes the test takers succeed. Later, Johnson (1992) experimented in the forms of writing, which found that the English level of the test takers who immigrate into America before seven years old shows no significant difference with the natives while the level of those who immigrate after seven shows decreasing trend as they grow older. The researcher attributes the differences of learning English before and after seven years old to physiological factor. However, it is worth noting that this experiment also found the degenerating stage of language learning begins at seven years old rather than what Lenneberg said at adolescence. This indicates that even though the critical period exists, when it begins is an inconclusive issue. Through his own study, Patkwosky (1980) found that it is possible for the critical period for second language acquisition to exist. He found that in the syntax, the learners who are younger than 15 years old are better than those who are exposed to language after 15. Among all the factors Patkwosky has tested in his research, the age is the most remarkable factor that influences the success of second language learning in his final conclusion. This study result is almost completely consistent with the Critical Period Hypothesis. Christine Weber Foxhe and Helen Neville (1999) applied the approach of combined behaviorism and event-related potentials to record and contrast the brain electrical activities of Chinese-English bilinguals whose native tongue is Chinese when they comprehend English sentences. Through the experiment, they think that the critical period 
for some language knowledge acquisition is before adolescence while others may be at other stages. It can thus be seen that there not only exists the critical period for language acquisition but also many kinds of critical periods. The previous studies indicate that there exists a critical period for second language acquisition. Language learning after the critical period is relevantly difficult. The adults that lack some learning advantages can also learn second language well.

\section{The Introduction to Several Essays About the Critical Period Hypothesis for Language Acquisition}

\section{The Implications of the Critical Period Hypothesis on College English Teaching}

Acquisition of second language is quite a complicated process which involves not only the factors such as social and cultural factors, but also the physiological factors of the learners their own (PENG, 2006). Among various physiological factors, it is no doubt that age is a very important factor that influences second language acquisition. As for the Critical Period Hypothesis for language acquisition, recently, it is widely believed that the stage of the critical period for language acquisition is from two years old to early puberty (10-12). He also believes that there are multiple critical periods for language acquisition. As a result, he draws several enlightenment from the multiple Critical Period Hypothesis. That is, from the aspects of college English speaking teaching, college English vocabulary and grammar teaching and college English listening, reading, and writing teaching, he airs his opinions of the inspiration.

\section{The Implications of the Critical Period Hypothesis for Second Language Acquisition on English Teaching}

CHU Li-li (2013) at first gives conventional research details of the Critical Period Hypothesis in her paper. Then she analyzes some examples related to the Critical Period Hypothesis such as the case of "Genie" and the case of "the wolf child" in Pathways to Psychology. Through these cases, she concludes that in the early growth period of children there exists a vital period - the critical period. She also believes that the cases above only instruct the learners who start at an early age have advantages over those who start late. Other relevant factors that influence language acquisition can not be ignored. After that she mentions a research of this area done by SHU Ding-fang, a famous linguist in China. The research results show that "the onset age of foreign language learning is not 'the earlier the better'. People who start to learn language at 20 to 30 years old can also obtain great results". Finally she concludes that there are a majority of factors that influence English teaching. As English teachers, we should have a comprehensive consideration of the factors that influence language learning.

\section{On English Language Teaching in Primary Schools From the Perspective of the Theory of Critical Period of Language Acquisition}

HUANG Xiao-yuan (2011) introduces some research results of the critical period for language acquisition and second language learning such as the research of Johnson and Newport, which is considered as the best evidence that supports the Critical Period Hypothesis in the area of second language acquisition, and the research of LIU Zhen-qian, which shows the existence of multiple critical periods, etc. From that, she gets some implications on primary school English teaching in our country from the aspects of the onset age and the key point of primary school teaching. 


\section{The Critical Period Hypothesis and English Language Learning in China}

The idea of the critical period originated from the researches on the behavioral development of some animals (DU, 2006). Recently, in the area of second language acquisition, some scholars modified it and thus generated a sensitive period hypothesis. That is to say, in language learning process there is a sensitive period of different language levels, such as the aspects of phonetics, syntax, semantics, etc. The writer believes that the only positive development advantage of learning second language earlier is phonetics. And she also thinks that the optimal age of foreign language formal learning in China is about 10 years old or later. Lastly, she points out some problems that should be focused on in primary school English teaching. For instance, attention should be paid to cultivating children's learning interests and teachers' ability, the improvement of teaching material, teaching aids, teaching methods, and teaching facilities.

\section{The Critical Period Hypothesis and Child English Teaching}

According to GUAN Wei (2011), grasping the native language is the foundation and the pronunciation is the most crucial thing in preschool foreign language learning. Second language learning of children in the critical period is easily affected by other factors such as the factors of mother language, language environment, interest and motivation, region, and faculty. Foreign language learning is not "the earlier the better", and the critical period does not have absoluteness. To be clear, we should explore some basic conditions that children's learning foreign language should be provided with. For example, the language environment and strategies that are appropriate to learn foreign language for children, teach children in accordance with their aptitudes.

\section{The Comparison Among the Five Essays}

\section{The Similarities Among These Essays}

At first, they all think that the Critical Period Hypothesis for second language acquisition does not have absoluteness. Second language learning is limited by many factors like language environment, teaching levels, learners themselves, etc. The factor of the learner age is a quite significant element. Secondly, second language learning is not the earlier the better. An individual who learns a foreign language after the critical period for language learning also has the ability to learn the language well, though he or she may not learn very well. Thirdly, the only possible advantage of learning a foreign language early is that it does well in pronunciation. Fourthly, those who start to learn foreign languages in childhood certainly have advantages, whether he or she receives regular school education for language learning or language acquisition in natural environment. Finally, in primary school English teaching, teachers should establish student-centered, relaxed and harmonious classroom language environment. It is of great importance to arouse the English teaching interests of the pupils. The adults have an advantage in writing.

\section{The Differences Among These Essays}

According to the Critical Period Hypothesis for second language acquisition, most of the writers consider that in most regions of our country, the onset age of English teaching should be 9 to 10 years old, which is about Grade 3 of primary school. At that age, the first language acquisition of children has nearly finished so that the wear rate of language has been slower. In addition, the intervention of second language would not have interference in the acquisition of the mother language. At the same time, children at that age are still in the critical 
period for language acquisition. Students who start to learn English in junior middle school first Grade 13 to 14 years old have missed the best age of phonetic acquisition. However, the best age for Chinese students to learn a foreign language is about 10 years old or later (DU, 2006). In detail, if the objective conditions are not adequate, it is not easy to offer English courses in primary schools. A buffer is necessary, and the formal English teaching could start until junior school.

The age of 16 is the critical period that influences grammar acquisition (PENG, 2006). As for the phonetics, listening, speaking, and vocabulary teaching, he thinks that the critical period is at the stage of primary school. But in GUAN Wei's view, adults have a greater capability in syntax and morphology.

\section{The Implications on English Teaching}

According to the rule and characteristics of the child's physical and mental development, the child English educators are supposed to apply some teaching means such as picture talk, singing, games, and performance. Let the children listen to the materials that are appropriate to their age and whose pronunciation and intonation is fluent and correct as much as possible. Teachers must create more opportunities for the children to listen and speak and create more language context that is helpful for the children to understand foreign languages and express in foreign languages.

In the stage of primary school English teaching, the top priority is phonology teaching. Reading aloud and imitating is the primary path. The input should be more comprehensible and have a simple code. Teaching and materials should be based on the life experience of the children. And teachers need to focus on the function of visualizing teaching. Otherwise, the learning and applying of polite formula is very important. The critical period for vocabulary acquisition is both in primary and secondary education stages. Therefore, students at these stages are supposed to improve their vocabulary as much as possible.

As for the college students, they should pay attention to the practice of reading and writing. In college English learning, as long as the students spend more time, their writing level will improve. Additionally, English teachers must spend more time and energy in cultivating the students' ability of English language application.

\section{Conclusion}

According to the Critical Period Hypothesis for language acquisition, the best age for the students in our country to learn English is about nine years old. As for the students of different stages, the teachers have to teach in accordance with the students' characteristics and aptitudes. Moreover, it is of great importance to be clear about their critical period for different language aspects and capture the critical period to apply correspondent teaching strategies and teaching methods. In English teaching, the teachers should think about all the factors that influence second language learning instead of simply attaching importance to the factor of age.

\section{References}

Asher, J., \& Garcia, R. (1969). The optimal age to learn a foreign language. Modern Language Journal, 53(5), 34-41.

CHEN, B. G., \& PENG, R. L. (2001). The critical period of language acquisition and suggestion to the language learning. Psychological Development and Education, 17(1), 52-57.

CHU, L. L. (2013). On the enlightenment of second language acquisition theory in English teaching. English Square, 11, 65-66. DU, L. X. (2006). The critical period hypothesis and English language learning in China. Journal of Anyang Institute of Technology, 6, 138-139. 
Ellis, R. (2013). The study of second language acquisition (2nd ed., p. 22). Shanghai: Shanghai Foreign Language Education Press. Fromkin, V., Rodman, R., \& Hyams, N. (1983). An introduction to language (8th ed., p. 67). Beijing: Pecking University Press.

GUAN, W. (2011). The critical period hypothesis of second language acquisition and children's English teaching. Theory Observe, $1,108-109$.

GUI, S. C. (2005). Psycholinguistics (new ed., p. 142). Shanghai: Shanghai Foreign Language Education Press.

HUANG, X. Y. (2011). On English language teaching in primary schools from the perspective of the theory of critical period of language acquisition. Journal of Qiongzhou University, 18(1), 129-130.

Johnson, J. (1989). Critical period effects in second language learning: The influence of maturational state on the acquisition of English as a second language. Cognitive Psychology, 21, 60-99.

Krashen, S. (1982). Child-adult difference in second language acquisition (p. 43). Rowley Mass: Newbury House.

Lenneberg, E. (1967). Biological foundations of language (p. 31). New York: Wiley-Blackwell.

LIU, Z. Q. (2003). A critique of the critical period hypothesis in L2 acquisition. Contemporary Linguistics, 2, 158-172.

Newport, E. (1990). Maturational constraints on language learning. Cognitive Science, 14, 11-28.

Oyama, S. (1978). A sensitive period in the acquisition of a non-native phonological system. Journal of Psycholinguistic Research, $5(3), 261-285$.

PENG, H. L. (2006). Critical period hypothesis on the teaching of college English language acquisition. Journal of Leshan Teachers College, 4, 125-128.

Seliger, H. (1978). Implications of a multiple critical periods hypothesis for second language learning (p. 78). New York: Academic Press.

SHU, D. F. (2004). FLT in China: Problems and suggested solutions (p. 142). Shanghai: Shanghai Foreign Language Education Press.

WANG, M. H. (2015). A study on the relationship between age onset of English learning and English achievement. Theory and Practice in Language Studies, 1, 164-169. 